\title{
EVALUATION OF HIGHWAY MAINTENANCE PERFORMANCE USING DATA ENVELOPMENT ANALYSIS (DEA) IN TAIWAN
}

\author{
Lung-Chuang Wang \\ Department of Civil Engineering, National Taipei University of Technology, Taiwan, R.O.C. \\ Hsiu-Yu Tsai \\ Department of Civil Engineering, National Taipei University of Technology, Taiwan, R.O.C., tsaihy@pie.com.tw
}

Follow this and additional works at: https://jmstt.ntou.edu.tw/journal

Part of the Civil and Environmental Engineering Commons

\footnotetext{
Recommended Citation

Wang, Lung-Chuang and Tsai, Hsiu-Yu (2009) "EVALUATION OF HIGHWAY MAINTENANCE PERFORMANCE USING DATA ENVELOPMENT ANALYSIS (DEA) IN TAIWAN," Journal of Marine Science and Technology. Vol. 17: Iss. 2, Article 9.

DOI: $10.51400 / 2709-6998.1969$

Available at: https://jmstt.ntou.edu.tw/journal/vol17/iss2/9

This Research Article is brought to you for free and open access by Journal of Marine Science and Technology. It has been accepted for inclusion in Journal of Marine Science and Technology by an authorized editor of Journal of Marine Science and Technology.
} 


\title{
EVALUATION OF HIGHWAY MAINTENANCE PERFORMANCE USING DATA ENVELOPMENT ANALYSIS (DEA) IN TAIWAN
}

\author{
Lung-Chuang Wang* and Hsiu-Yu Tsai*
}

\begin{abstract}
Key words: data envelopment analysis, maintenance performance evaluation, highway maintenance, Directorate General of Highways.
\end{abstract}

\begin{abstract}
Data Envelopment Analysis (DEA) is utilized in this study to evaluate the performance of 31 highway maintenance sections belonging to the Directorate General of Highways (DGH). The input data are total amount of budget, manpower, and machines, and the output data are length of highway, routine expenditure on maintenance, budget for salvage, and the revenue from helping digging and mending roads. In order to make the analysis fit to the goals of highway maintenance sections, the weights of some inputs and outputs are restricted. The analytical models of CCR and BCC are used to estimate productive efficiency, technical efficiency, and scale efficiency of each section. Furthermore, the A\&P model is used to sort the efficient sections. For those sections with less efficiency, short-term and long-term improvement suggestions are proposed. Finally, there is a preliminary discussion about the feasibility of using DEA in evaluation of section merging programs.
\end{abstract}

\section{INTRODUCTION}

Every profit-making organization will establish maximum profit as its primary goal, and strive to pursue an optimized productive efficiency by turning "inputs" into "outputs". So, financial indicators can provide a basis for evaluation of productive efficiency. However, the governmental bodies, serving as nonprofit organizations, cannot evaluate the "inputs" and "outputs" only by financial indicators. Under the governance of Directorate General of Highways (DGH), there are over $8,000 \mathrm{~km}$ provincial and county highways, about 4,000 bridges and 200 tunnels. And, DGH has 1-5 highway maintenance departments, under which there are 31 highway maintenance sections. These sections, acting as front-line en-

Paper submitted 01/15/08; accepted 07/13/08. Author for correspondence: Hsiu-Yu Tsai (e-mail: tsaihy@pie.com.tw).

*Department of Civil Engineering, National Taipei University of Technology, Taiwan, R.O.C gineering maintenance units, have great influence upon the quality of highway with their performance. Therefore, a scientific analytical approach shall be required to grasp the maintenance performance of highway maintenance sections, and provide suggestions for improving them based on the performance evaluation results.

The researches on pavement material and construction techniques of highway are emphasized for a long time, however, the researches on maintenance performance are not so popular. Wei and Schonfeld propose a cost-effect method to evaluate the utility of road maintenance [15]. This method can take the interaction between user cost and maintenance cost under consideration, and help decision maker to reduce cost and improve maintenance efficiency. During the process of this method, each different factor has to be transferred into same utility unit. However, it is not easy in practice. Stivers proposes a service quality evaluation system in National Cooperative Highway Research Program (NCHRP) [12]. This system may predict budget requirement and resource allocation more exactly by setting key indexes and weights of maintenance. Since the weights are decided by experts, it is not easy to avoid the influences of subjective preference.

The data used in this study are derived from the statistical data of year 2002 of DGH. According to the characteristics of highways, this study categorizes the sections into two types-hill and plain, then identify and analyze necessary inputs/ outputs via Delphi-Analytic Hierarchy Process (DAHP), and determine the weight restrictions of inputs/outputs. Moreover, Data Envelopment Analysis (DEA) is used to analyze the utilization resources of Directorate General of Highways, such as maintenance expenses, manpower, and machines, as well as actual maintenance achievements. Subsequently, for those sections with less efficiency, this study proposes suggestions for improvement with regard to the magnitude and direction of maintenance according to DEA.

\section{DATA ENVELOPMENT ANALYSIS (DEA)}

DEA adopts the economic efficiency concept of "Pareto Optimality," namely "it is impossible to improve some individuals' performance without prejudice to the others under a 
certain economic condition". Any Decision Making Unit (DMU) is called as an effective production point if their production scale and cost combination take a leading position on the frontier, otherwise, it's called as an inefficient production point.

DEA had the following advantages $[8,9]$ :

(1) Suitable for evaluation of many inputs and outputs, without requiring the functional relation between inputs and outputs. It also eliminates the barrier to build functions and estimate parameters.

(2) Identify the performance simply by a single composite indicator (maximum efficiency value of 1 , less efficiency between $0 \sim 1)$.

(3) Provide a relative comparison for Decision Making Units (DMU).

(4) Independent of human factors, the weight number of every DMU is optimum since the weight of inputs/outputs is sourced from mathematical programming.

(5) Since relative efficiency value is independent of measuring unit, inputs/outputs have different units.

(6) Provide a basis of improving the management with regard to the magnitude and direction of maintenance for those sections with less efficiency.

Yet, DEA is subjected to the following constraints $[5,11]$ :

(1) Since data-sensitive efficiency frontier is obtained from mathematical programming, the data shall be extremely accurate, otherwise, the shape and efficiency value of efficiency frontier are to be affected.

(2) The relative efficiency value can be only evaluated from units with a certain amount and of the same property, other than those with little amount and of different properties.

(3) Difficult to handle the outputs with negative values.

(4) Analytical results cannot be explained easily if samples have Outlier.

(5) The findings of analyses are relative rather than absolute.

(6) Given the institutional structures, DEA adopts the efficiency perspectives to perform the analyses. Therefore, it is not easy to evaluate the given institutional structures.

\section{Common Analytical Model}

Data Envelopment Analysis is available with two common models of CCR and BCC:

\section{1) CCR Model}

CCR model, initiated by Charnes, Cooper and Rhodes [4], is a basic model of DEA. In practical applications, mathematical programming method is used to calculate CCR model by the following formula, whereby the optimum value $\left(\theta^{*}\right)$ of $\theta$ can be obtained from linear programming, i.e. efficiency value of DMU:

$$
\begin{array}{ll}
\text { Min } \quad & h_{k}=\theta-\varepsilon\left(\sum_{i=1}^{m} s_{i}^{-}+\sum_{r=1}^{s} s_{r}^{+}\right) \\
\text {s.t. } \quad \sum_{j=1}^{n} \lambda_{j} X_{i j}-\theta X_{i k}+s_{i}^{-}=0 \\
\\
\qquad \sum_{j=1}^{n} \lambda_{j} Y_{r j}-s_{r}^{+}=Y_{r k} \\
\lambda_{j}, s_{i}^{-}, s_{r}^{+} \geq 0 \quad j=1, \ldots, n \quad i=1, \ldots, m \quad r=1, \ldots, s
\end{array}
$$

Where, the meanings of variables are represented below:

$h_{k}$ : efficiency value of no. $k$ unit.

$s_{i}^{-}$: slack.

$s_{r}^{+}$: surplus.

$x_{i j}$ : no. $i$ input of no. $j$ unit.

$y_{r j}:$ no. $r$ output of no. $j$ unit.

$\varepsilon$ : non-Archimedean small number, an extremely small positive value, is usually represented by $10^{-6}$. It aims to offer positive weight coefficients $u_{r}, v_{i}$ (without 0 ), thus ensuring that every input or output is not ignored.

Given some Constant Returns to scale, it's feasible to estimate its relative productive efficiency $(\mathrm{PE})$, with the concept represented by the formula below:

$$
\text { Productive efficiency }(\mathrm{PE})=\frac{\text { Sum of weighted outputs }}{\text { Sum of weighted inputs }}
$$

\section{2) BCC Model}

BCC model, initiated by Banker, Charnes and Cooper [2], is used to improve CCR model for Constant Returns to Scale into a model for Various Returns to scale. Technical Efficiency (TE) can be inducted from BCC model, and Scale Efficiency (SE) from formula (3):

$$
\mathrm{PE}=\mathrm{SE} \times \mathrm{TE}
$$

Where PE: Production efficiency.

SE: Scale efficiency.

TE: Technical efficiency.

Scale efficiency is represented by the ratio of existing inputs (or outputs) of DMUs to the inputs (or outputs) of optimal production scale. During analysis phase, productive efficiency can be inducted from CCR model, and technical efficiency from BCC model. Furthermore, scale efficiency can be obtained through their division, while it's possible to judge if the returns to scale of DMU is in an increasing, constant or decreasing state.

In practical applications, mathematical programming method is used to calculate BCC model by formula (4), whereby 
the optimum value $\left(\theta^{*}\right)$ of $\theta$ can be obtained from linear programming, i.e. efficiency value of DMU:

$$
\begin{array}{ll}
\text { Min } & h_{k}=\theta-\varepsilon\left(\sum_{i=1}^{m} s_{i}^{-}+\sum_{r=1}^{s} s_{r}^{+}\right) \\
\text {s.t. } & \sum_{j=1}^{n} \lambda_{j} X_{i j}-\theta X_{i k}+s_{i}^{-}=0 \\
& \sum_{j=1}^{n} \lambda_{j} Y_{r j}-s_{r}^{+}=Y_{r k} \\
& \sum_{j=1}^{n} \lambda_{j}=1 \\
s_{i}^{-}, s_{r}^{+} \geq 0 \quad j=1, \ldots, n \quad i=1, \ldots, m \quad r=1, \ldots, s
\end{array}
$$

Where, $\lambda^{*}$ can be used to judge the trend of returns to scale:

$\sum \lambda^{*}<1$, indicating increasing returns to scale.

$\sum \lambda^{*}=1$, indicating constant returns to scale.

$\sum \lambda^{*}>1$, indicating decreasing returns to scale.

\section{3) A\&P Model}

If DMU is located on efficiency frontier when CCR model is used to analyze productive efficiency, it belongs to an efficient DMU, and the optimal solution must conform to the conditions of formula (5) (* indicating optimal solution):

$$
\theta^{*}=1 \text { and } s_{i}^{-*}=s_{r}^{+*}=0
$$

However, since the efficiency value of efficient DMU is evaluated as 1 if CCR model is applied, it's impossible to judge the quality only by efficiency value in the presence of more than two efficient DMUs. In such case, A\&P models shall be required for comparison of efficient DMUs.

A\&P model, developed by Andersen and Petersen [1], is used to sort DMUs with efficiency value of 1 . According to the calculating principle of efficiency frontier, DMU shall be removed to recalculate the efficiency value by newly acquired efficiency frontier. Thus, for DMU with original efficiency value as 1 , its efficiency value may be more than 1 if it's calculated by A\&P model. This value is called "efficiency indicator". As shown in Fig. 1, efficiency value at point D is 1, and the efficiency indicator of point $\mathrm{D}$ is $\frac{O D^{*}}{O D}>1$ after being calculated by A\&P model. The bigger the indicator value, the more efficient DMU is, but it has no any influence upon original DMU with less efficiency.

\section{Improvement of DMU with Less Efficiency}

If analytical results of CCR or BCC model cannot meet the condition of formula (5), this DMU is proved to be one with less efficiency not located in efficiency frontier. In order to

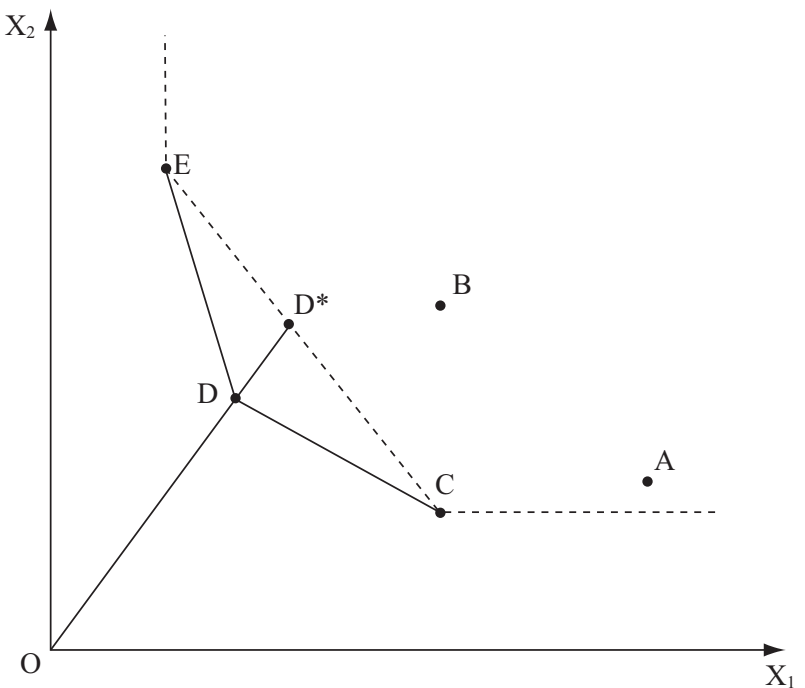

Fig. 1. Efficiency indicator calculated by A\&P model.

promote its efficiency and position itself into efficiency frontier, the inputs and outputs shall be adjusted according to the calculating principle of DEA:

$$
\begin{aligned}
& \text { Input to be reduced } \Delta X_{i k}=X_{i k}-\left(\theta^{*} X_{i k}-s_{i}^{-^{*}}\right) \\
& \text { Output to be increased } \Delta Y_{r k}=\left(Y_{i k}+s_{r}^{+^{*}}\right)-Y_{r k}
\end{aligned}
$$

Where, $\left(\theta^{*} X_{i k}-s_{i}^{-^{*}}\right)$ and $\left(Y_{r k}+s_{r}^{+^{*}}\right)$ are input or output benchmark indicator values of DMUs with less efficiency.

\section{PERFORMANCE OF HIGHWAY MAINTENANCE SECTIONS BELONGING TO DIRECTORATE GENERAL OF HIGHWAYS}

This study is directed to highway maintenance sections under Directorate General of Highways (DGH). As nonprofit public services of clear goals, they have achieved some maintenance results using many resources such as budget and manpower. Given the fact of similar property and sufficient quantity for 31 highway maintenance sections, DEA is utilized to analyze the relative efficiency and performance among these sections.

Golany and Roll sum up several major procedures of using DEA to evaluate performance [6]. Referring to their conclusion, this study develops the following analytical process.

The first step of DEA is to define the evaluation objects. DMU for evaluation shall have the following features [7]:

(1) Similar working property: DMU must have the same organization objectives and perform the same tasks.

(2) Similar working environment: working in the same environment.

(3) Same inputs and outputs: except for intensity or magnitude. 


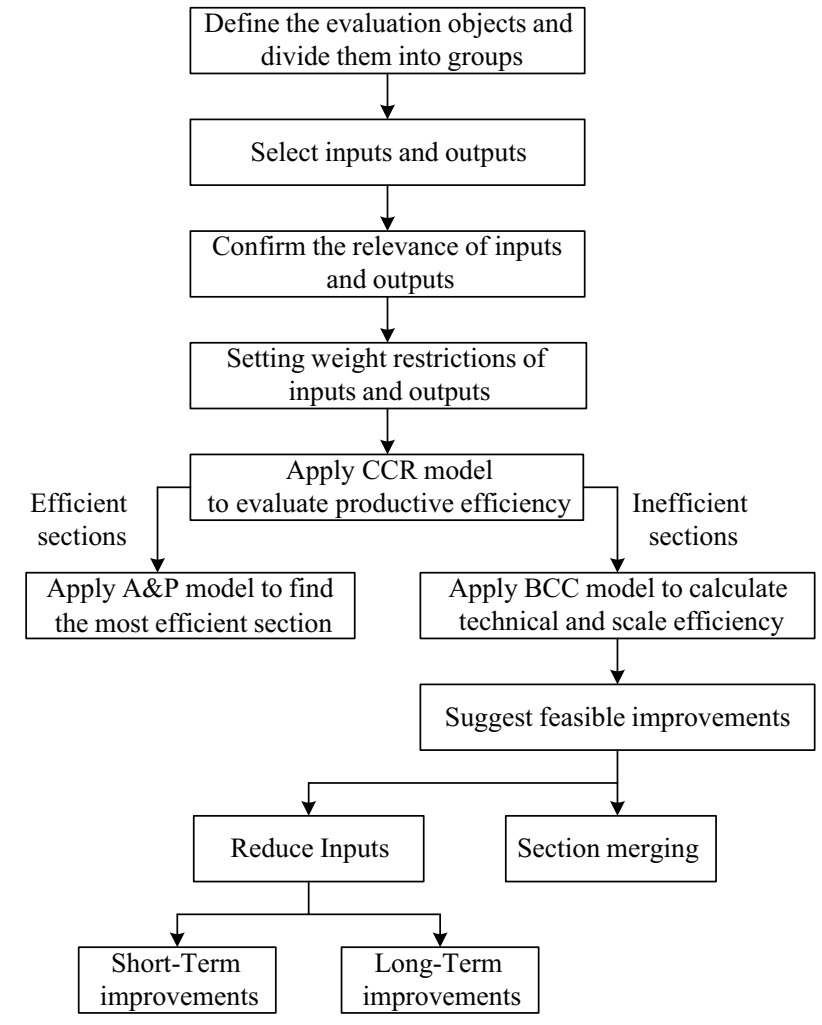

Fig. 2. The flowchart of process in this study.

The 31 highway maintenance section under Directorate General of Highways, belonging to the same hierarchical organization, have the same organization objectives such as provincial and county highways, and are applicable to the same laws and regulations. Moreover, they utilize the same category of resources, such as budget, manpower and machines, and perform similar tasks, thus serving as appropriate evaluation objects of Data Envelopment Analysis.

\section{Division of Highway Maintenance Sections}

DEA model aims to compare the relative efficiency of all DMUs. During evaluation phase, inputs and outputs of all DMUs must be the same, so isomorphic class shall be required for the evaluation objects. Otherwise, evaluation results account for nothing. It can be learnt from actual maintenance experience that, the focus of highway maintenance may vary from different terrains. Generally, more frequent maintenance shall be required at plain highway owing to bigger traffic volume than in hill highway. To the contrary, hill highway will undergo natural disasters more frequently owing to the topographic characteristics. To yield more representative analytical results via DEA, this study categorize 31 highway maintenance sections into two types--15 hill and 16 plain maintenance sections according to topographic characteristics, and then evaluate separately their performance by DEA, with the analytical results shown in Table 1.
Table 1. Classification table of hill and plain highway maintenance sections.

\begin{tabular}{|c|c|c|c|}
\hline Type & Quantity & $\begin{array}{c}\text { Serial No. of } \\
\text { sections }\end{array}$ & \multicolumn{1}{c|}{ Characteristics } \\
\hline Hill & 15 & $1-15$ & $\begin{array}{l}\text { Over 50\% of the length in highway } \\
\text { section is hill or mountain. }\end{array}$ \\
\hline Plain & 16 & $16-31$ & $\begin{array}{l}\text { Over 50\% of the length in highway } \\
\text { section is plain. }\end{array}$ \\
\hline
\end{tabular}

\section{Selection of Inputs and Outputs}

\section{1) Conditions of Inputs and Outputs}

The second step of Data Envelopment Analysis is to select inputs and outputs. "Output" means concrete measurement items for realizing organization objectives, while "input" means various resources in favor of outputs. The following factors shall be taken into account during selection of inputs and outputs [7]:

a. Organization objectives: firstly establish organization objectives, then define inputs and outputs, and further identify the evaluation indicators.

b. Property of data: data analysis is generally relying on ratio scale or interval scale. Inputs or outputs must be a nonnegative number. If one item is 0 , it's replaced by an extremely small positive number, such as $10^{-6}$, in order to avoid bogus evaluation result.

c. Relationship of inputs and outputs: inputs or outputs must comply with "isotonicity", namely, outputs shall increase with the inputs.

d. Amount of inputs and outputs: inputs and outputs shall maintain under one half of DMU, otherwise, it will cause insufficient discriminability. Therefore, inputs and outputs shall be reduced or incorporated if necessary.

Pursuant to "Regulations on Highway Construction, Maintenance and Management", highway maintenance covers roadbeds, side slopes, road surfaces, bridges, tunnels, drainage facilities, traffic safety devices and landscaping, etc. Meanwhile, highway maintenance sections shall assume management responsibilities of over ground facilities within their ownership, bottom of roadbed, destruction of underground pipelines, excavation \& backfilling and utilization rights of highway. In general, DEA places a biggest restriction upon selection of inputs and outputs, since it's subjected to the constraint of relevant requirements and quantity of DMUs. On the other hand, the screening process of items also helps the management units understand the relevance of resources and achievements while grasping the most important indicators.

\section{2) Determination of Inputs and Outputs}

In order to facilitate the selection of inputs/outputs, and enhance the objectivity and expandability of outputs, this 
study developed a Delphi-Analytic Hierarchy Process (DAHP) by incorporating the advantages of AHP (Analytic Hierarchy Process) and Delphi technique. From identification of organization objectives to rational selection of inputs and outputs, this study has collected suggestions from a panel of experts, and boosted their understanding of unique problems via information transfer among them, thereby minimizing efficiently the possibility of subjective deviation arising from AHP. In this regard, the planners shall not make any judgment during preliminary research phase of inputs/outputs, but collect all solicited and unsolicited information, such as interviews of policy-makers and inquiry of advisers, and build up a framework of inputs and outputs based on Delphi opinion survey from a panel of experts. Next, they shall perform pairwise comparison in AHP, investigate the preference structure of experts and policy-makers, and then repetitively incorporate Delphi method to grasp the significance of inputs and outputs [14].

Through a panel of experts including 10 scholars, managers and senior engineers in the field of highway maintenance, this study has selected the inputs and outputs for performance evaluation of highway maintenance section, with the results shown in Fig. 3.

Since inputs and outputs shall maintain under one half of DMU, otherwise, it will cause insufficient discriminability, so some items of similar property are incorporated by the suggestions of experts. Finally, this study has analyzed the following three inputs and four outputs, with the detailed description below (Fig. 4):

\section{a. Inputs}

In general, the inputs of an engineering construction include expenses, manpower and machines. Thus, this study utilizes manpower, budget, and quantity of maintenance machines as inputs of highway maintenance sections.

(a) Manpower: including technical and administrative staff of highway maintenance sections. Apart from engineering construction, highway maintenance sections require the support of administrative departments during maintenance work.

(b) Budget: including annual budget allotment of highway maintenance sections involving maintenance of bridges \& culverts, safety protection, landscaping protection and salvage.

(c) Quantity of maintenance machines: including all machines related to highway maintenance, such as road rollers, etc.

\section{b. Outputs}

This study utilizes the length of highway, routine expenditure on maintenance, budget for salvage, and the revenue from helping digging and mending roads as outputs of highway maintenance sections. For routine expenditure on maintenance and budget for salvage that involve a variety of highway maintenance works and make it difficult to quantify the en-

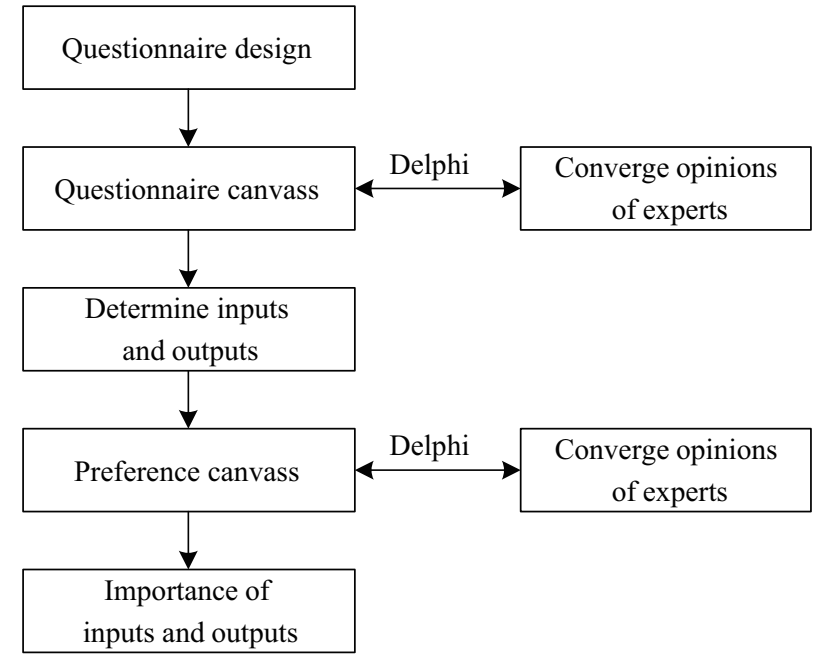

Fig. 3. The flowchart of Delphi--Analytic Hierarchy Process [13].

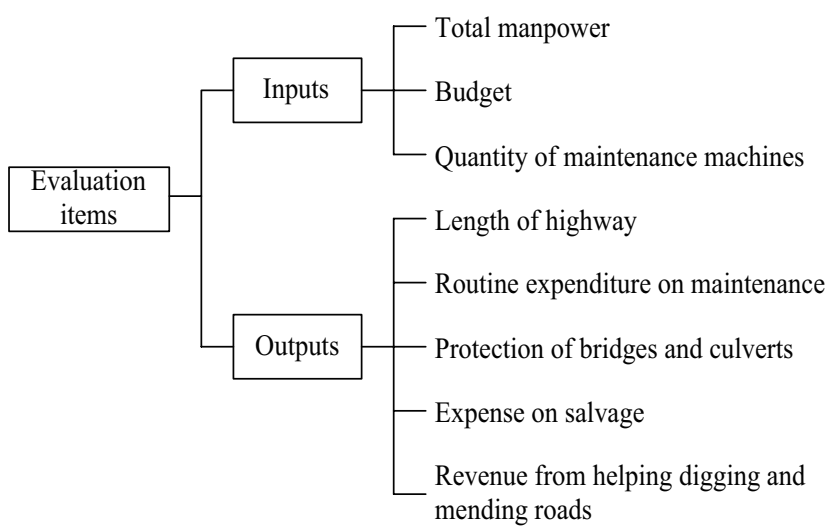

Fig. 4. Selections of inputs and outputs.

gineering achievements, the engineering implementation shall be represented by actual expenditure according to the suggestions of a panel of experts.

(a) Length of highway: including total length of provincial and county highways.

(b) Routine expenditure on maintenance: including the expenses on protection of bridges \& culverts, road surfaces and safety protection measures as well as landscaping maintenance.

(c) Expense on salvage: representing typical outputs, including actual expenses for emergent repair of damaged highway in the case of natural disasters.

(d) Revenue from helping digging and mending roads: Given the fact of buried pipelines or other facilities along highways, the relevant pipeline bodies shall coordinate with the highway authorities to help dig and mend them after shift or repair, and pay some charges accordingly. This study utilizes the revenue from helping digging and mending roads as one typical output of highway maintenance sections. 
There are 7 items, of which including 3 inputs and 4 outputs. The quantity of hill and plain highway maintenance sections amounts to 15 and 16 respectively, more than 2 times of the sum of inputs and outputs. So, the evaluation results prove sufficient discriminability according to empirical law.

\section{3) Relevance of Inputs and Outputs}

As inputs and outputs screened by DEA method must logically account for the influential factors of the efficiency, there shall be a positive correlation between inputs and outputs, namely, the outputs shall increase with the inputs. For this purpose, a correlation matrix is applied for correlation analysis, while a correlation coefficient is taken to estimate the relationship and interaction of two variables. This study intends to calculate separately inputs and outputs of hill and plain highway maintenance sections via correlation matrix, with the results listed in Table 2. It can thus be learnt that, there is a positive correlation between inputs and outputs of two types of highway maintenance sections, which meets the requirements of DEA.

\section{Weight Restrictions of Inputs and Outputs}

Since original concept of DEA didn't set the weight values of various inputs and outputs, every DMU can reach its individual optimum state. Therefore, when DEA is traditionally used for analysis, more attentions are paid to "which items shall be included into inputs and outputs for evaluation," rather than setting the weights of various inputs and outputs. Nonetheless, this concept may differ from actual situation, for various authorities may attach different importance to inputs and outputs considering their own central tasks and organization objectives. Thus, no any relatively important relation is set between outputs, which differs much from actual practices. In so doing, it is also not able to get an appropriate and reasonable explanation in terms of economic or administrative perspectives. Consequently, in order to obtain values that are closer to the real situation, Thompson et al. constrain the model by setting the weights of various inputs and outputs [13]. Regarding how to set the weights, we can consult experts and scholars.

Based on DAHP analysis, it can be found that some inputs and outputs differ a lot in terms of importance. In order to comply with the goals and objectives of highway maintenance, this study has formulated different importance for some inputs and outputs. According to the suggestion of a panel of experts, "total manpower" plays a most important role in all inputs. In addition, "revenue from helping digging and mending roads" is an item of lowest importance in all outputs since maintenance sections only benefit from it when providing assistance to other pipeline units. Though highway salvage is universally considered as the first priority in the case of traffic accident, and is urgently required due to its highest importance in outputs, it doesn't often happen at all highway maintenance sections. If a biggest restriction is placed on the weight of salvage expense, it will exert a serious impact upon the performance of
Table 2. Relevant matrix of inputs and outputs of highway maintenance sections.

\begin{tabular}{|c|l|c|c|c|}
\hline $\begin{array}{c}\text { Types of } \\
\text { Section }\end{array}$ & Inputs & Budget & $\begin{array}{c}\text { Total } \\
\text { manpower }\end{array}$ & $\begin{array}{c}\text { Quantity of } \\
\text { maintenance } \\
\text { machines }\end{array}$ \\
\hline Hill type & $\begin{array}{l}\text { Length of highway } \\
\text { section }\end{array}$ & 0.17 & 0.22 & 0.17 \\
\cline { 2 - 5 } & $\begin{array}{l}\text { Routine } \\
\text { expenditure on } \\
\text { maintenance }\end{array}$ & 0.28 & 0.47 & 0.23 \\
\cline { 2 - 5 } & $\begin{array}{l}\text { Expense on } \\
\text { salvage }\end{array}$ & 0.72 & 0.18 & 0.39 \\
\cline { 2 - 5 } $\begin{array}{l}\text { Revenue from } \\
\text { helping digging } \\
\text { and mending roads }\end{array}$ & 0.41 & 0.19 & 0.41 \\
\hline \multirow{2}{*}{ Plain type } & $\begin{array}{l}\text { Length of highway } \\
\text { section }\end{array}$ & 0.58 & 0.76 & 0.43 \\
\cline { 2 - 5 } & $\begin{array}{l}\text { Routine } \\
\text { expenditure on } \\
\text { maintenance }\end{array}$ & 0.47 & 0.05 & 0.32 \\
\cline { 2 - 5 } $\begin{array}{l}\text { Expense on } \\
\text { salvage }\end{array}$ & 0.75 & 0.74 & 0.31 \\
\hline $\begin{array}{l}\text { Revenue from } \\
\text { helping digging } \\
\text { and mending roads }\end{array}$ & 0.39 & 0.32 & 0.58 \\
\hline
\end{tabular}

highway maintenance sections without accidents, thus distorting possibly evaluation results. For this reasons, this study hasn't placed a restriction upon the weight of salvage expense. In sum, this study has added relatively restrictive conditions for the weights of some inputs and outputs, with its aim of matching the free adjustment feature of DEA weights and conforming to actual practices:

(1) Inputs: weight of "total manpower," an item of highest importance in all inputs.

(2) Outputs: "revenue from helping digging and mending roads," an item of lowest importance in all outputs.

\section{Selection of Evaluation Model}

This study has analyzed separately hill and plain highway maintenance sections via CCR model, and identified DMUs with relative efficiency (efficiency value $=100 \%$ ) and relative inefficiency (efficiency value $<100 \%$ ) after obtaining productive efficiency. Then, it has sorted via A\&P model DMUs with productive efficiency of 1 , and subsequently analyzed them via BCC model, so as to induct technical efficiency and scale efficiency of highway maintenance sections.

CCR model is used to estimate productive efficiency. The reasons that lead to productive efficiency less than $100 \%$ include: (1) waste of resources arising from poor management, i.e. technical efficiency (BCC efficiency) hasn't reached 100\%; (2) highway maintenance section is not well-positioned in an optimum scale state, i.e. scale efficiency hasn't reached $100 \%$. 
If the scale efficiency of highway maintenance section is $100 \%$, it shows that highway maintenance section is positioned in a state of constant returns to scale (CRS), otherwise, highway maintenance section is oversized or undersized. If it's undersized, it's positioned in an increasing returns to scale (IRS). If it's oversized, it's positioned in a decreasing returns to scale (DRS).

\section{ANALYTICAL RESULTS}

Given the fact of a complex calculating process of DEA, this study utilizes a computer software package. The calculating results are as follows:

\section{Analytical Results of Hill Highway Maintenance Sections}

\section{1) Analytical Results of CCR Model}

The analytical results of hill highway maintenance sections under CCR model are listed in Column 3 of Table 3, indicating productive efficiency of highway maintenance sections. Among the analytical results, the productive efficiency of 9 highway maintenance sections has reached $100 \%$, accounting for $60 \%$ of all hill highway maintenance sections. The remaining 6 highway maintenance sections belong to those with less productive efficiency, accounting for $40 \%$ of all hill highway maintenance sections, of which the lowest productive efficiency is $50 \%$.

\section{2) Analytical Results of A\&P Model}

To identify the sorting of 9 highway maintenance sections with productive efficiency of $100 \%$, this study utilizes A\&P model for this purpose. As listed in column 2 of Table 3, no. 7 highway maintenance section has a highest efficiency indicator during analysis via A\&P model, thus no. 7 presents a best performance.

\section{3) Analytical Results of BCC Model}

The analytical results of hill highway maintenance sections under BCC model are listed in column 4 of Table 3, indicating technical efficiency of highway maintenance sections. Column 5 lists the value of technical efficiency divided by productive efficiency, indicating the scale efficiency of highway maintenance sections.

Among the analytical results, the technical efficiency of 11 highway maintenance sections has reached $100 \%$, accounting for $73 \%$ of all hill highway maintenance sections. The remaining 4 highway maintenance sections belong to those with less technical efficiency, accounting for $27 \%$ of all hill highway maintenance sections, of which the lowest technical efficiency is $71 \%$. The scale efficiency of 9 highway maintenance sections has reached $100 \%$, accounting for $60 \%$ of all hill highway maintenance sections. The remaining 6 highway maintenance sections aren't well-sized, accounting for $40 \%$ of all hill highway maintenance sections, of which the lowest scale efficiency is $50 \%$.
Table 3. Analytical results of hill highway maintenance sections.

\begin{tabular}{|c|c|c|c|c|c|}
\hline No. & $\begin{array}{c}\text { Efficiency } \\
\text { Indicator }\end{array}$ & $\begin{array}{c}\text { Productive } \\
\text { Efficiency }\end{array}$ & $\begin{array}{c}\text { Technical } \\
\text { Efficiency }\end{array}$ & $\begin{array}{c}\text { Scale } \\
\text { Efficiency }\end{array}$ & $\begin{array}{c}\text { Returns to } \\
\text { Scale }\end{array}$ \\
\hline 1 & $125 \%$ & $100 \%$ & $100 \%$ & $100 \%$ & CRS \\
\hline 2 & $74 \%$ & $74 \%$ & $91 \%$ & $82 \%$ & IRS \\
\hline 3 & $117 \%$ & $100 \%$ & $100 \%$ & $100 \%$ & CRS \\
\hline 4 & $322 \%$ & $100 \%$ & $100 \%$ & $100 \%$ & CRS \\
\hline 5 & $86 \%$ & $86 \%$ & $87 \%$ & $99 \%$ & IRS \\
\hline 6 & $67 \%$ & $67 \%$ & $73 \%$ & $92 \%$ & IRS \\
\hline 7 & $393 \%$ & $100 \%$ & $100 \%$ & $100 \%$ & CRS \\
\hline 8 & $119 \%$ & $100 \%$ & $100 \%$ & $100 \%$ & CRS \\
\hline 9 & $102 \%$ & $100 \%$ & $100 \%$ & $100 \%$ & CRS \\
\hline 10 & $100 \%$ & $100 \%$ & $100 \%$ & $100 \%$ & CRS \\
\hline 11 & $99.9 \%$ & $99.9 \%$ & $100 \%$ & $99.9 \%$ & IRS \\
\hline 12 & $103 \%$ & $100 \%$ & $100 \%$ & $100 \%$ & CRS \\
\hline 13 & $50 \%$ & $50 \%$ & $100 \%$ & $50 \%$ & IRS \\
\hline 14 & $109 \%$ & $100 \%$ & $100 \%$ & $100 \%$ & CRS \\
\hline 15 & $55 \%$ & $55 \%$ & $71 \%$ & $76 \%$ & IRS \\
\hline
\end{tabular}

Among highway maintenance sections without productive efficiency, no. 2, 5, 6, 11, 13 and 15 highway maintenance sections are in an increasing returns to scale (IRS), indicating these sections shall be incorporated or expanded to promote their scale efficiency. It's noteworthy that technical efficiency of no. 11 and 13 highway maintenance sections has reached $100 \%$, indicating they have fully turned the resources into outputs, but the overall efficiency hasn't reached efficiency frontier owing to undersize. Comparatively, there is a bigger room for no. 2, 5, 6 and 15 highway maintenance sections with regard to technical efficiency and scale efficiency.

\section{Analytical Results of Plain Highway Maintenance Sections}

\section{1) Analytical Results of CCR Model}

The analytical results of plain highway maintenance sections under CCR model are listed in column 3 of Table 4, indicating productive efficiency of highway maintenance sections. Among the analytical results, the productive efficiency of 10 highway maintenance sections has reached $100 \%$, accounting for $63 \%$ of all plain highway maintenance sections. The remaining 6 highway maintenance sections belong to those with less productive efficiency, accounting for $37 \%$ of all plain highway maintenance sections, of which the lowest productive efficiency is $65 \%$.

\section{2) Analytical Results of A\&P Model}

To identify the sorting of 10 highway maintenance sections with productive efficiency of $100 \%$, this study utilizes A\&P model for this purpose. As listed in column 2 of Table 4, no. 19 highway maintenance section has a highest efficiency indicator during analysis via A\&P model, thus no. 19 presents a best performance. 
Table 4. Analytical results of plain highway maintenance sections.

\begin{tabular}{|c|c|c|c|c|c|}
\hline No. & $\begin{array}{c}\text { Efficiency } \\
\text { Indicator }\end{array}$ & $\begin{array}{c}\text { Productive } \\
\text { Efficiency }\end{array}$ & $\begin{array}{c}\text { Technical } \\
\text { Efficiency }\end{array}$ & $\begin{array}{c}\text { Scale } \\
\text { Efficiency }\end{array}$ & $\begin{array}{c}\text { Returns to } \\
\text { Scale }\end{array}$ \\
\hline 16 & $115 \%$ & $100 \%$ & $100 \%$ & $100 \%$ & CRS \\
\hline 17 & $75 \%$ & $75 \%$ & $78 \%$ & $95 \%$ & IRS \\
\hline 18 & $143 \%$ & $100 \%$ & $100 \%$ & $100 \%$ & CRS \\
\hline 19 & $461 \%$ & $100 \%$ & $100 \%$ & $100 \%$ & CRS \\
\hline 20 & $65 \%$ & $65 \%$ & $69 \%$ & $94 \%$ & IRS \\
\hline 21 & $103 \%$ & $100 \%$ & $100 \%$ & $100 \%$ & CRS \\
\hline 22 & $131 \%$ & $100 \%$ & $100 \%$ & $100 \%$ & CRS \\
\hline 23 & $107 \%$ & $100 \%$ & $100 \%$ & $100 \%$ & CRS \\
\hline 24 & $104 \%$ & $100 \%$ & $100 \%$ & $100 \%$ & CRS \\
\hline 25 & $81 \%$ & $81 \%$ & $100 \%$ & $81 \%$ & IRS \\
\hline 26 & $81 \%$ & $81 \%$ & $82 \%$ & $98 \%$ & IRS \\
\hline 27 & $69 \%$ & $69 \%$ & $100 \%$ & $69 \%$ & IRS \\
\hline 28 & $119 \%$ & $100 \%$ & $100 \%$ & $100 \%$ & CRS \\
\hline 29 & $149 \%$ & $100 \%$ & $100 \%$ & $100 \%$ & CRS \\
\hline 30 & $94 \%$ & $94 \%$ & $100 \%$ & $94 \%$ & IRS \\
\hline 31 & $120 \%$ & $100 \%$ & $100 \%$ & $100 \%$ & CRS \\
\hline
\end{tabular}

\section{3) Analytical Results of BCC Model}

The analytical results of plain highway maintenance sections under BCC model are listed in column 4 of Table 4, indicating technical efficiency of highway maintenance sections. Column 5 lists the value of technical efficiency divided by productive efficiency, indicating the scale efficiency of highway maintenance sections.

Among the analytical results, the technical efficiency of 13 highway maintenance sections has reached $100 \%$, accounting for $81 \%$ of all plain highway maintenance sections. The remaining 3 highway maintenance sections belong to those with less technical efficiency, accounting for 19\% of all plain highway maintenance sections, of which the lowest technical efficiency is $69 \%$. The scale efficiency of 10 highway maintenance sections has reached $100 \%$, accounting for $62.5 \%$ of all plain highway maintenance sections. The remaining 6 highway maintenance sections aren't well-sized, accounting for $37.5 \%$ of all plain highway maintenance sections, of which the lowest scale efficiency is $69 \%$.

Among highway maintenance sections without productive efficiency, no. 17, 20, 25, 26, 27 and 30 highway maintenance sections are in an increasing returns to scale (IRS), indicating these sections shall be incorporated or expanded to promote their scale efficiency. It's noteworthy that technical efficiency (BCC efficiency) of no. 25, 27 and 30 highway maintenance sections has reached $100 \%$, indicating they have fully turned the resources into outputs, but the overall efficiency hasn't reached efficiency frontier owing to undersize. Comparatively, there is a bigger room for no. 17, 20 and 26 highway maintenance sections with regard to technical efficiency and scale efficiency.

\section{SUGGESTIONS FOR IMPROVEMENT}

Based on efficiency value and slack, DEA can provide the direction and magnitude for improvement of inefficient highway maintenance sections. Since this study performs an input-oriented analysis, and some outputs of maintenance works cannot be manually controlled or adjusted within a short term, the suggestions here to focus on improvement of inputs. The objective and direction for improvement can be analyzed through formula (7):

$$
\text { Inputs to be reduced } \Delta X_{i k}=X_{i k}-\left(\theta^{*} X_{i k}-s_{i}^{-*}\right)
$$

This study initiates two feasible directions for improvement:

\section{Suggestion One for Improvement: Reduce Inputs Gradually}

\section{1) Short-Term Package--Promote Technical Efficiency}

The efficiency value calculated by BCC model is a technical efficiency, which may provide a reference for short-term improvement package [3]. In other words, for highway maintenance sections with productive efficiency less than $100 \%$, the short-term improvement objective is to turn inputs efficiently into outputs as far as possible, namely, spurring technical efficiency to reach $100 \%$. With a reference to the estimation results of hill and plain highway maintenance section via BCC model, the inputs to be reduced within a short term are listed in Table 5.

It can thus be learnt that, technical efficiency (BCC efficiency) of no. 2, 5, 6, 15 hill highway maintenance sections and no. 17, 20 and 26 plain highway maintenance sections hasn't reached $100 \%$, all of which shall be considered as sections to be improved within a short term.

\section{2) Long-Term Package--Promote Productive Efficiency}

The efficiency value calculated by CCR model is a technical efficiency, which may provide a reference for long-term improvement package [3]. In other words, for highway maintenance sections with productive efficiency less than $100 \%$, the long-term improvement objective is to make productive efficiency reach $100 \%$, in addition to aforementioned shortterm suggestions for improvement of technical efficiency up to $100 \%$. With a reference to the estimation results of hill and plain highway maintenance section via CCR model, the inputs to be reduced within a long term are listed in Table 6 .

\section{Suggestion Two for Improvement: Incorporate Highway Maintenance Sections}

It could thus be found that, DEA can, based on efficiency value calculated from CCR model, estimate the target amount of inputs to be reduced with a long term. However, from the perspective of best practice, a basic amount of inputs shall be required to maintain the normal operation of a highway 
Table 5. Short-term package-amount of inputs to be reduced by highway maintenance sections.

\begin{tabular}{|c|c|c|c|c|c|}
\hline \multirow{2}{*}{$\begin{array}{l}\text { Types of } \\
\text { sections }\end{array}$} & \multirow[b]{2}{*}{ No. } & \multirow{2}{*}{$\begin{array}{l}\text { Technical } \\
\text { Efficiency }\end{array}$} & \multicolumn{3}{|c|}{ Amount of Inputs to be Reduced } \\
\hline & & & Budget & $\begin{array}{c}\text { Total } \\
\text { Manpower }\end{array}$ & $\begin{array}{c}\text { Maintenance } \\
\text { Machine }\end{array}$ \\
\hline \multirow{15}{*}{$\begin{array}{l}\text { Hill } \\
\text { type }\end{array}$} & 1 & $100 \%$ & 0 & 0 & 0 \\
\hline & 2 & $91 \%$ & 6903 & 5 & 1 \\
\hline & 3 & $100 \%$ & 0 & 0 & 0 \\
\hline & 4 & $100 \%$ & 0 & 0 & 0 \\
\hline & 5 & $87 \%$ & 4834 & 8 & 2 \\
\hline & 6 & $73 \%$ & 2647 & 16 & 6 \\
\hline & 7 & $100 \%$ & 0 & 0 & 0 \\
\hline & 8 & $100 \%$ & 0 & 0 & 0 \\
\hline & 9 & $100 \%$ & 0 & 0 & 0 \\
\hline & 10 & $100 \%$ & 0 & 0 & 0 \\
\hline & 11 & $100 \%$ & 0 & 0 & 0 \\
\hline & 12 & $100 \%$ & 0 & 0 & 0 \\
\hline & 13 & $100 \%$ & 0 & 0 & 0 \\
\hline & 14 & $100 \%$ & 0 & 0 & 0 \\
\hline & 15 & $71 \%$ & 33387 & 18 & 3 \\
\hline \multirow{16}{*}{$\begin{array}{l}\text { Plain } \\
\text { type }\end{array}$} & 16 & $100 \%$ & 0 & 0 & 0 \\
\hline & 17 & $78 \%$ & 6484 & 13 & 8 \\
\hline & 18 & $100 \%$ & 0 & 0 & 0 \\
\hline & 19 & $100 \%$ & 0 & 0 & 0 \\
\hline & 20 & $69 \%$ & 4780 & 22 & 14 \\
\hline & 21 & $100 \%$ & 0 & 0 & 0 \\
\hline & 22 & $100 \%$ & 0 & 0 & 0 \\
\hline & 23 & $100 \%$ & 0 & 0 & 0 \\
\hline & 24 & $100 \%$ & 0 & 0 & 0 \\
\hline & 25 & $100 \%$ & 0 & 0 & 0 \\
\hline & 26 & $82 \%$ & 4194 & 10 & 3 \\
\hline & 27 & $100 \%$ & 0 & 0 & 0 \\
\hline & 28 & $100 \%$ & 0 & 0 & 0 \\
\hline & 29 & $100 \%$ & 0 & 0 & 0 \\
\hline & 30 & $100 \%$ & 0 & 0 & 0 \\
\hline & 31 & $100 \%$ & 0 & 0 & 0 \\
\hline
\end{tabular}

maintenance section. If the long-term target amount calculated by mathematical method of DEA is less than the necessary basic amount, this long-term objective is unlikely realized. In such case, organization reshuffling must be taken into account, namely, highway maintenance sections are to be reorganized and incorporated.

For instance, no. 13 highway maintenance section has a total manpower of 28 , which may be reduced to 14 according to the calculating results of Table 6 . But, the practical experience demonstrates that this number is too insufficient to maintain normal operation of a highway maintenance section. For this reason, attentions shall be paid to its reorganization and incorporation.

Rock studied organization reshuffling based on efficiency theory, information theory, proxy theory, market force
Table 6. Long-term package-amount of inputs to be reduced by highway maintenance sections.

\begin{tabular}{|c|c|c|c|c|c|}
\hline \multirow{2}{*}{$\begin{array}{l}\text { Types of } \\
\text { sections }\end{array}$} & \multirow[b]{2}{*}{ No. } & \multirow{2}{*}{$\begin{array}{l}\text { Productive } \\
\text { Efficiency }\end{array}$} & \multicolumn{3}{|c|}{ Amount of Inputs to be Reduced } \\
\hline & & & Budget & $\begin{array}{c}\text { Total } \\
\text { Manpower }\end{array}$ & $\begin{array}{c}\text { Maintenance } \\
\text { Machine }\end{array}$ \\
\hline \multirow{15}{*}{$\begin{array}{l}\text { Hill } \\
\text { type }\end{array}$} & 1 & $100 \%$ & 0 & 0 & 0 \\
\hline & 2 & $74 \%$ & 8907 & 13 & 4 \\
\hline & 3 & $100 \%$ & 0 & 0 & 0 \\
\hline & 4 & $100 \%$ & 0 & 0 & 0 \\
\hline & 5 & $86 \%$ & 5060 & 8 & 2 \\
\hline & 6 & $67 \%$ & 3250 & 20 & 10 \\
\hline & 7 & $100 \%$ & 0 & 0 & 0 \\
\hline & 8 & $100 \%$ & 0 & 0 & 0 \\
\hline & 9 & $100 \%$ & 0 & 0 & 0 \\
\hline & 10 & $100 \%$ & 0 & 0 & 0 \\
\hline & 11 & $100 \%$ & 12 & 0 & 7 \\
\hline & 12 & $100 \%$ & 0 & 0 & 0 \\
\hline & 13 & $50 \%$ & 4852 & 14 & 9 \\
\hline & 14 & $100 \%$ & 0 & 0 & 0 \\
\hline & 15 & $55 \%$ & 36797 & 28 & 5 \\
\hline \multirow{16}{*}{$\begin{array}{l}\text { Plain } \\
\text { type }\end{array}$} & 16 & $100 \%$ & 0 & 0 & 0 \\
\hline & 17 & $75 \%$ & 6434 & 15 & 8 \\
\hline & 18 & $100 \%$ & 0 & 0 & 0 \\
\hline & 19 & $100 \%$ & 0 & 0 & 0 \\
\hline & 20 & $65 \%$ & 5471 & 25 & 16 \\
\hline & 21 & $100 \%$ & 0 & 0 & 0 \\
\hline & 22 & $100 \%$ & 0 & 0 & 0 \\
\hline & 23 & $100 \%$ & 0 & 0 & 0 \\
\hline & 24 & $100 \%$ & 0 & 0 & 0 \\
\hline & 25 & $81 \%$ & 1541 & 7 & 4 \\
\hline & 26 & $81 \%$ & 4508 & 11 & 3 \\
\hline & 27 & $69 \%$ & 2151 & 12 & 2 \\
\hline & 28 & $100 \%$ & 0 & 0 & 0 \\
\hline & 29 & $100 \%$ & 0 & 0 & 0 \\
\hline & 30 & $94 \%$ & 448 & 3 & 6 \\
\hline & 31 & $100 \%$ & 0 & 0 & 0 \\
\hline
\end{tabular}

theory and tax saving theory [10]. Still, DEA can provide a support in selection of reorganization packages from the perspective of efficiency theory. Since organization reshuffling of highway maintenance section involves a wide range of issues, this study just shows some examples on how to provide DEA to evaluate reorganization packages as a supportive tool.

For example, no. 5, 13 highway maintenance section has a total manpower of 58 and 28 respectively. According to the analytical results listed in Table 3 , the productive efficiency hasn't reached $100 \%$, showing a state of increasing returns to scale (IRS), thus incorporation shall be considered to promote their scales for an increased scale efficiency. After incorporation of no. 5 and 13 highway maintenance sections, the productive efficiency is recalculated by CCR model, showing that inputs shall be reduced (listed in Table 7) if long-term 
Table 7. Long-term target value of inputs after no. 5 and 13 sections are incorporated.

\begin{tabular}{|c|c|r|r|c|}
\hline \multirow{2}{*}{ No. } & \multirow{2}{*}{$\begin{array}{c}\text { Productive } \\
\text { Efficiency }\end{array}$} & \multicolumn{3}{|c|}{ Amount of Inputs to be Reduced } \\
\cline { 3 - 5 } & & Budget & $\begin{array}{c}\text { Total } \\
\text { Manpower }\end{array}$ & $\begin{array}{c}\text { Maintenance } \\
\text { Machine }\end{array}$ \\
\hline 1 & $100 \%$ & 0 & 0 & 0 \\
\hline 2 & $74 \%$ & 8907 & 13 & 4 \\
\hline 3 & $100 \%$ & 0 & 0 & 0 \\
\hline 4 & $100 \%$ & 0 & 0 & 0 \\
\hline $5+13$ & $77 \%$ & 10486 & 19 & 7 \\
\hline 6 & $67 \%$ & 3250 & 20 & 10 \\
\hline 7 & $100 \%$ & 0 & 0 & 0 \\
\hline 8 & $100 \%$ & 0 & 0 & 0 \\
\hline 9 & $100 \%$ & 0 & 0 & 0 \\
\hline 10 & $100 \%$ & 0 & 0 & 0 \\
\hline 11 & $100 \%$ & 12 & 1 & 7 \\
\hline 12 & $100 \%$ & 0 & 0 & 0 \\
\hline 14 & $100 \%$ & 0 & 0 & 0 \\
\hline 15 & $55 \%$ & 36797 & 28 & 5 \\
\hline
\end{tabular}

productive efficiency of these sections is to reach $100 \%$. It can be seen that, after incorporation of no. 5 and 13 highway maintenance section, the total manpower shall decline by 19 to 67 in a long term run, higher than the minimum manpower requirement for a single highway maintenance section--a feasible package.

\section{CONCLUSIONS}

According to the topographic characteristics, this study categorizes 31 highway maintenance sections under Directorate General of Highways into two types - hill (15) and plain (16). The data used in this study are derived from the statistical data of year 2002. Moreover, this study utilizes the total amount of budget, total manpower, and maintenance machines as inputs, and the length of highway section, routine expenditure on maintenance, budget for salvage, and the revenue from helping digging and mending roads as outputs. In order to make the results fit to the goals and needs of highway maintenance, this study weights the inputs and outputs to respectively restrict their relative magnitude. Based on analytical results, there are 9 hill highway maintenance sections whose productive efficiency is $100 \%$, showing a relative efficiency, among which no. 7 presents a best performance. Meanwhile, there are 10 plain highway maintenance section whose productive efficiency is $100 \%$, showing a relative efficiency, among which no. 19 presents a best performance. This analysis also shows that, for either hill or plain highway maintenance sections with a scale efficiency less than $100 \%$, they are in an Increasing returns to scale (IRS), indicating these sections with relative insufficiency are undersized.

DEA can be used to provide the magnitude and direction for improvement of inefficient highway maintenance sections.
This study proposes short-term and long-term target of inputs to be reduced by highway maintenance sections, and emphasizes that no. 2, 5, 6, 15 hill highway maintenance sections and 17, 20, 26 plain highway maintenance sections could be granted first priority for improvement within a short-term. Besides, this study shows an example on how to provide DEA to evaluate reorganization packages as a supportive tool.

Based on the cross section of a certain time point, this study performs analysis according to the statistical data of year 2002 involving all highway maintenance sections. In addition, when DEA is applied for analysis, most of inputs and outputs are quantifiable variables that can be controlled by policy-makers. Nonetheless, some of them are unquantifiable and uncontrollable external factors that have influence upon practical practice. It's thus recommended that subsequent researchers should explore the influential factors of overall performance of highway maintenance sections through analysis of long-term trend and external environmental variables.

In the paragraph of suggestions for improvement packages, this study puts forward some benchmarks for short-term and long-term improvement of various sections under existing organization framework. It's noteworthy that, for all highway maintenance sections with productive efficiency less than $100 \%$, their scale efficiency is very poor, indicating that their performance is adversely affected by improper scale. Therefore, it's worthy to make an in-depth discussion of how to optimize the scale of highway maintenance sections via organization reshuffling or other efficient policies.

\section{REFERENCES}

1. Andersen, P. and Petersen, N. C., "A procedure for ranking efficient units in data envelopment analysis," Management Science, Vol. 39, No. 10, pp. 1261-1264 (1993).

2. Banker, R. D., Charnes, A., and Cooper, W. W., "Some models for estimating technical and scale inefficiencies in DEA," Management Science, Vol. 30, No. 9, pp. 1078-1092 (1984).

3. Chang, R. B., Research on Operational Performance of Private Technological Institutes in Taiwan, Dissertation, Chung Hua University Graduate Institute of Industrial Management, Hsinchu, Taiwan (2003).

4. Charnes, A., Cooper, W. W., and Rhodes, E., "Measuring the efficiency of decision making units," European Journal of Operational Research, Vol. 2, No. 6, pp. 429-444 (1978).

5. Doyle, J. R. and Grew, R. H., "Comparing products using data envelopment analysis,” Omega, Vol. 19, No. 6, pp. 631-638 (1991).

6. Golany, B. and Roll, Y., "An application procedure for data envelopment analysis," Omega, Vol. 17, No. 3, pp. 237-250 (1989).

7. Kao, C., Hwang, S. N., and Toshiyuki, S., Evaluation of Management Performance--Data Envelopment Analysis, Hua Tian Culture Co. LTD., Taipei (2003).

8. Lewin, A. Y. and Minton, J. W., "Determining organizational effectiveness: another look, and an agenda for research," Management Science, Vol. 32, No. 5, pp. 514-538 (1986).

9. Lewin, A. Y., Morey, R. C., and Cook, T. J., "Evaluating the administrative efficiency of courts," Omega, Vol. 10, No. 4, pp. 401-411 (1982).

10. Rock, M. L., The Morers and Acquisition Handbook, McGraw-Hill, NY (1987).

11. Schmid, A. A., Property, Power and Public Choice: An Inquiry into Law and Economics, Praeger, New York (1987). 
12. Stivers, M. L., Maintenance QA Program Implementation Manual, NCHRP report 422, National Academy Press (1999).

13. Thompson, R. G., Langemeier, L. N., Lee, C. H., Lee, E., and Thrall, R. M., "Comparative site evaluations for locating high energy lab in Texas," Interfaces, Vol. 16, pp. 1380-1395 (1986).

14. Wang, L. C. and Chang, F. C., “A study on developing the optimal pro- curing model for earthquake restoration in Taiwan," Civil and Hydraulic Engineering, Vol. 27, No. 4, pp. 28-43 (2001).

15. Wei, C. H. and Schonfeld, P. M., "A research framework for cost-effective highway maintenance planning," Public Works Management \& Policy, Vol. 2, No. 4, pp. 340-349 (1998). 